\title{
Apego y lactancia natural
}

\author{
FERNANDO PINTO L. ${ }^{1}$
}

1. Neurólogo Infantil, Jefe Servicio de Pediatría del Hospital Regional Coyhaique. Profesor Titular, Facultad de Medicina, Universidad de Chile.

Presidente. Sociedad Chilena de Pediatría 2001-2002.

\section{ABSTRACT \\ Breast feeding and mother-newborn attachment}

Breast feeding and mother-newborn attachment during the first 6 months of life are responsible in the future physical, emotional and intellectual health of newborns and their mothers. Since the ancient work of Harlow, evaluating the maternal behaviour in mammals, to recent studies and reports from nutritional experts of the Paediatrics American Academy allow us a better understanding of the physiology and the importance of breast feeding and mother-newborn attachment in human development, besides the great challenge that health professionals have in its promotion and prevention of pathologic mother-newborn attachment.

(Key words: mother-newborn attachment, breast feeding, sensitive period, pathologic mother-newborn attachment).

Rev Chil Pediatr 2007; 78 (Supl 1): 96-102

\section{RESUMEN}

El Apego y la Lactancia Natural Exclusiva, durante los 6 primeros meses de vida, han demostrado ser responsables fundamentales en la futura salud física, emocional e intelectual de los Recién Nacidos y sus Madre. Desde los antiguos trabajos de Harlow, evaluando la conducta maternal en mamíferos, hasta los estudios más recientes y los reportes de los expertos en lactancia de la Academia Americana de Pediatría podemos comprender mejor la fisiología e importancia del Apego y Lactancia Natural en el desarrollo del ser humano y el gran desafío que tienen los profesionales de la salud para este siglo en su promoción y en la prevención del apego patológico y sus consecuencias.

(Palabras clave: Apego, lactancia natural, Bonding relación madre-hijo, período sensitivo, apego patológico).

Rev Chil Pediatr 2007; 78 (Supl 1): 96-102

El apego y la lactancia natural han cobrado mucha importancia en las últimas dos décadas, tanto a nivel mundial como nacional, debido a que, un Buen Apego favorece los lazos afectivos entre la madre y su hijo y se relaciona con mayor duración y mejor calidad de la lac- tancia natural, lo que a futuro, estimula un mejor desarrollo psicomotor y una salud óptima para el niño.

La lactancia natural exclusiva, al menos durante los primeros seis meses de vida, por si sola determina una disminución de la morbi- 
mortalidad en el niño y en su propia madre. Resulta de extraordinario interés destacar, que investigaciones de los últimos años demuestran fehacientemente, que los niños que al menos fueron alimentados durante seis meses con lactancia natural exclusiva son más inteligentes y presentan con menos frecuencia diferentes enfermedades como asma bronquial, enfermedades atópicas, enfermedades gastrointestinales, leucemias y otros cánceres, obesidad, diabetes mellitus tipo I y II, enfermedades autoinmunitarias, etc., en comparación con los niños que no tuvieron ese privilegio. Al largo plazo continúan con mejor salud, con menor incidencia de enfermedades cardiovasculares, cerebrovasculares, cánceres y enfermedades autoinmunitarias en general.

Pero también las madres se benefician al corto y largo plazo, con una anticoncepción natural durante la lactancia, mayor rapidez en la recuperación del peso previo al embarazo, menor incidencia de osteoporosis, menor incidencia de cáncer de mama y ovarios.

Existe abundante bibliografía que apoya lo anterior y además lo relaciona, inclusive, con otros problemas de la infancia, como por ejemplo Maltrato Infantil. Se ha observado que un porcentaje de los niños maltratados presenta el antecedente de "mal apego" inicial o "disfunción" del mismo, frecuentemente asociado a prematuridad o patología perinatal. El Niño Vulnerable, que enferma con frecuencia, pese a que los estudios inmunológicos y otros de laboratorio resultan normales y el Mal Progreso Pondoestatural ("Falla en la Medración"), sin explicación nutricional o endocrinológica, también han sido relacionados a deficiencia o disfunción en el apego.

Más que paradójico es el hecho de que ningún país en el mundo, pese a lo contundente de las evidencias científicas, tenga leyes sociales o legislación, que genuinamente protejan el apego y la lactancia natural exclusiva a través de estímulos y licencias prenatales y postnatales, por los períodos adecuados (mínimo de un mes prenatal y de seis meses postnatales), considerando que se podría disminuir la prematuridad y gran parte de la patología del niño y su madre, tanto al corto y mediano, como al largo plazo.

La Organización Internacional del Trabajo
(OIT) en su legislación comparada, exhibe grandes diferencias entre los distintos países afiliados, en lo relativo a las licencias pre y postnatales. Desde la ausencia de las mismas (en algunos estados de USA deben ahorrar vacaciones legales para ese período), hasta la posibilidad de conservar la plaza de trabajo sin remuneración por 3 años, como sucede en Estonia o la posibilidad de acceder a un trabajo de media jornada laboral mientras el niño es lactante como en algunos países europeos.

Pareciera ser que la protección del apego y lactancia natural exclusiva no ha sido la posición política de ningún país, sino más bien, conquistas laborales de las mujeres trabajadoras a lo largo del mundo en las últimas cinco décadas. Más bien se tiende a castigar la maternidad, en vez de premiarla y ello está constituyendo el drama de esos mismos países, cuya población ha envejecido y la fuerza laboral para mantener al país y sus jubilados, se va viendo disminuida.

Chile tiene la posibilidad de ser pionero en este campo. En el año 2001, durante el Congreso de Pediatría se emitió la "Declaración de Pucón", que defiende los derechos del recién nacido y su madre. Esta fue enviada a todas las Sociedades de Pediatría del mundo y a los Ministerios de Salud de los países afiliados a la OIT. En el año 2002, la Sociedad Chilena de Pediatría entregó en la Oficina de Partes del Congreso Nacional un proyecto titulado "Prolongación de la Licencia Postnatal a Seis Meses, para proteger el Apego y Lactancia Natural", previamente conocido y aprobado por la Comisión de Salud de la Cámara de Diputados. Hoy sólo resta reactivar dicho proyecto, que fue apoyado y financiado en parte por la UNICEF, especialmente en el estudio de evaluación económica que forma parte de este número especial de la Revista. De legislarse y aprobarse, Chile sería el primer país en el mundo con la política de proteger el apego y la lactancia natural de acuerdo a las legítimas necesidades del recién nacido y su madre, basado en la medicina de las evidencias y no como consecuencia de conquistas laborales de la mujer trabajadora, aceptando el aporte científico de las Ramas y Comités de expertos de la Sociedad Chilena de Pediatría. 
El apego o Imprinting o Bonding, como se menciona en inglés, fue detectado científicamente por psicólogos experimentales, hace más de seis décadas. Ellos observaron que cuando se apartaba al cordero recién nacido de su madre inmediatamente después del alumbramiento por algunas horas, ésta no lo reconocía como hijo propio cuando le era devuelto. Más aún, se negaba a amamantarlo y hasta le podía agredir. Pero si no se interferían las primeras seis horas de vida del corderito junto a su madre y luego se les separaba, cuando éste retornaba al alero de su madre, ésta lo acogía, cuidaba y amamantaba con normalidad. Algo muy importante en relación al apego, ocurría en las primeras horas de vida del corderito junto a su madre, lo que determinaba las conductas posteriores. Estas horas iniciales fueron denominadas período sensitivo. El período sensitivo fue ratificado en todos los mamíferos estudiados. Dicho período, también lo encontramos en nuestra sabiduría y cultura popular. Es reconocido el hecho de que en nuestros campos, no se "molesta" durante el período sensitivo a los animales domésticos o a los de crianza.

Antes de los sociólogos y psicólogos experimentales, los artistas con su especial sensibilidad habían detectado y reflejado en sus obras muchos aspectos de la Relación Madre-Hijo, desde el Renacimiento a través de algunos bocetos de Miguel Angel, hasta el período del Impresionismo, especialmente con la pintora Mary Cassat, que dedica más de setenta cuadros a esta temática, a fines del siglo XIX.

A finales de la década de los sesenta, los doctores M. Klaus y J. Kennel en Cleveland (Ohio, USA), se preocuparon del tema y se preguntaron cómo se producía el apego y cuál era el período sensitivo en el ser humano. Para ello estudiaron en primer lugar los eventos importantes en la formación de una futura madre, separándoles en el tiempo en tres períodos:

- Antes del embarazo. Planificación del embarazo.

- Durante la gestación. Confirmación del embarazo, aceptación del mismo, movimientos fetales y aceptación del feto como individuo. En esa época no existía la ecografía obstétrica que hoy en día también juega un rol importante en la conducta materna al permitir la visualización activa del feto, reforzando las futuras conductas de apego.

- Después del parto. Nacimiento, ver, tocar, oler y reconocer al hijo y comienzo del apego inicial.

Los estudios sociológicos de variados grupos étnicos aislados, en distintas fases evolutivas desde el paleolítico en Australia, tribus indígenas de Africa y Amazonía y algunos reductos indígenas de USA aportaron un hecho muy interesante. Todos los grupos étnicos estudiados tenían algo en común: el parto era un evento privado donde se protegía la intimidad de la madre con su recién nacido, en las primeras horas de vida, para después transformarse en un evento social. Esas primeras horas, a la luz de los conocimientos actuales corresponden al Período Sensitivo.

Con estos antecedentes, en 1964, Klaus y colaboradores comenzaron un estudio prospectivo en dos hospitales pequeños de la ciudad de Guatemala (Experiencia de Guatemala), tras haber fracasado en sus intentos de definir el período sensitivo y apego inicial en hospitales de USA, debido a la tremenda medicalización del proceso de embarazo y parto, que impedía observar la conducta espontánea y natural de una madre con su recién nacido.

En dicha experiencia se organizaron dos grupos de madres. En el primer grupo, se permitía a las madres permanecer en íntimo contacto ("piel con piel") con su recién nacido, durante 45 minutos y luego se continuaba con la rutina habitual: llevar el recién nacido a la sala cuna y trasladarlo con su madre cada 4 horas para estimular e iniciar lactancia. Al segundo grupo se les retiraba el recién nacido inmediatamente después del parto, durante el alumbramiento, sin oportunidad de contacto inicial, y posteriormente se continuaba la misma rutina del primer grupo, trasladando al hijo a la sala cuna. Ambos grupos eran idénticos y comparables (primíparas, primigestas, de edades entre 18 y 25 años, embarazo normal y sano y con pareja estable), salvo en el hecho de que el primero tenía un contacto íntimo con su hijo durante 45 minutos. A los seis meses de vida, los lactantes del primer grupo pesaban en promedio 490 gramos más y la mayoría conserva- 
ba la lactancia natural exclusiva, en comparación con el segundo grupo. Al año se apreció en el primer grupo, un significativo mejor desarro1lo psicomotor. En el segundo grupo hubo mayor número de infecciones y consultas médicas por morbilidad durante el primer año de vida.

Estos hallazgos fueron suficientes para sospechar que efectivamente existía un período sensitivo en el ser humano y que en ese lapso de tiempo comienza una etapa muy importante del Apego.

Durante este período sensitivo se desarrolla un apego progresivo que se explica por las interacciones recíprocas entre la madre y su hijo en los primeros momentos de relación.

El recién nacido viene preparado para esta interacción. Normalmente los recién nacidos duermen la mayor parte del tiempo, en los primeros días de vida, con escasos momentos de alerta. Pero al nacer, al cabo de 3 a 5 minutos, comienzan un estado de alerta muy significativo de alrededor de 40 a 60 minutos, que es el más largo del primer mes de vida. Es durante esta alerta, donde el recién nacido está genéticamente preparado para esta mágica interacción. Si la práctica hospitalaria retira al bebé de su madre en este preciso período, priva a ambos de esta maravillosa vivencia inicial y disminuye parte de la calidad e intensidad del apego.

En esta primera interacción madre-hijo, ocurren muchos fenómenos interesantes. Primero la madre observa a su recién nacido ojo a ojo. El niño responde concentrando la mirada en su madre. Luego comienza a tocarlo delicadamente y de manera progresiva, comenzando generalmente por las manitos, luego los pies y finalmente el resto del cuerpo. La madre le habla suavemente con voz de tonalidad alta. El $\mathrm{RN}$ responde con algunos movimientos tenues de cara y manos; esto confirma a la madre que el niño está atento y en comunicación directa con ella. El niño llora. El llanto erecta los pezones maternos y estimula a las hormonas prolactina y ocitocina. Se produce una sincronía entre el lenguaje materno, cadencioso y los movimientos del niño. La madre lleva al $\mathrm{RN}$ al pezón y éste lo frota hasta que emerge la primera gota de calostro, plena de linfocitos $\mathrm{T}$, linfocitos B y macrófagos, que entregan al niño la clave de los anticuerpos a formar, para defenderse de la flora bacteriana de la piel materna. Estos primeros momentos e interacciones son primordiales en el inicio del apego.

Hoy sabemos que existe un Período Sensitivo, en el cual se producen los primeros pasos de apego, el que se irá reforzando día a día en los días sucesivos, hasta constituir el mayor lazo afectivo que existe en la humanidad: la relación madre-hijo, relación única que vincula al hijo con su madre de por vida. Es por esta fuerte relación que la madre provee el alimento y cuidado de su hijo con tal constancia y dedicación, que ello explica la supervivencia de nuestra especie en los últimos 200000 años, con períodos glaciales y grandes desastres naturales.

\section{¿Podemos favorecer el apego?}

Desde luego y ello implica educar a los humanos desde su más tierna infancia. El apego no es privativo de las mujeres, también se extiende a los varones con su descendencia.

Las niñitas y niños deben ser preparados para la maternidad y paternidad desde muy pequeños. Deben ir recibiendo la información acerca de la maternidad de acuerdo a su capacidad cognitiva, aprovechando toda instancia positiva respecto a este tema. Por ejemplo, vivenciando el embarazo de un familiar o amiga cercana, o el embarazo de una mascota. Transmitiendo experiencias positivas frente al tema. Evitando comentarios negativos como "el dolor del parto", "las molestias del embarazo"y otros, y fomentando "la maravilla de la maternidad ", "lo fascinante del embarazo", "lo extraordinario de la lactancia“, etc.

Se debe estimular en las niñitas los juegos con muñecas relativos a maternidad y lactancia.

Existe una clara diferencia entre niñitas que han recibido mensajes positivos frente a embarazo, parto y lactancia y aquellas que han recibido mensajes negativos. Las primeras son más proclives a la maternidad y por lo general tienen mejores embarazos, partos más fisiológicos y mayor calidad y duración de la lactancia, en comparación a las otras.

Durante el embarazo, se debe educar a la futura madre en todo lo relativo a las bondades 
del apego y la lactancia natural exclusiva, en lo posible incluyendo a su pareja. Se les debe enseñar que su recién nacido es una personita con capacidad de ver muy bien y en colores, y que puede escucharla desde las primeras horas de vida. Será capaz de reconocerla a través de su visión, audición y olfato. Y más aún que tratará de comunicarse con sus padres a través de un tenue lenguaje mímico-gestual, que ellos descubrirán de manera intuitiva e inequívoca.

Señalarles reiteradamente, que el hijo viene preparado para conocerles y comunicarse con ellos y que a la vez, ellos también estarán preparados para ese evento merced a la genética y la sabia naturaleza.

Durante el parto es recomendable la presencia del padre, para lo cual debiera ser preparado e instruido. Es fundamental que la madre, si no existe contraindicación médica ( $\mathrm{QQue}$ pocas veces existe!), tenga la oportunidad de permanecer al menos durante las tres primeras horas, en íntimo contacto con su hijo, estando éste desnudo y entre sus pechos, en contacto "piel con piel" y con la máxima privacidad que sea posible. Permitir que el recién nacido, a través de su olfato y movimientos reptantes se aproxime al pezón y comience a estimularle para inducir las hormonas prolactina y ocitocina, tan beneficiosas para el apego, la lactancia materna y la prevención de hemorragias uterinas después del parto.

En el puerperio inmediato, lo ideal es no separar a la madre de su hijo. Permitir que éste quede junto a ella, en una cuna anexa a su cama, donde sea posible mantener un contacto visual y táctil constante. Los profesionales de la salud serán responsables de supervisar un correcto inicio del apego y de la lactancia y aprovechar toda instancia educativa para esos padres.

Cuando la madre e hijo sean dados de alta y trasladados a su domicilio, es conveniente "por indicación médica" proteger al máximo la intimidad de la pareja y restringir las visitas de familiares y amigos, para permitir un progresivo ajuste en el apego y lactancia. Las visitas pueden ser diferidas por algunas semanas, hasta que la madre haya logrado una lactancia eficiente y se haya recuperado del cansancio y las molestias físicas posteriores al parto. Esto último previene angustia, disfunción de apego, agotamiento físico y garantiza una mejor calidad de lactancia. Desde entonces, será el pediatra, con el rango de médico de la familia, quien irá dirigiendo a los padres en esta nueva experiencia.

\section{¿Podemos detectar precozmente disfunción en el apego?}

La disfunción en el apego puede ser detectada, tanto en la madre como en el recién nacido, a través de una acuciosa observación clínica y conversando e interrogando a la madre. Debemos recordar que dicha disfunción es perjudicial tanto para la madre como para su hijo.

La madre con disfunción en apego, es una mujer tensa y angustiada, que se siente incompetente para criar y amamantar a su hijo porque básicamente no se puede comunicar con él y no entiende sus claves comunicacionales. No discrimina entre un llanto de hambre, de sueño, de enfermedad, de estar sucio e incómodo, o de otra naturaleza. Ello la impulsa a conductas, a veces, muy neuróticas, de sobrealimentación forzada, de excesivo número de mudas e inclusive consultar médico sin ser necesario. Esta situación de angustia e incompetencia, la va deprimiendo progresivamente hasta el grado de perder la motivación por su hijo, terminar la lactancia natural y llegar al extremo de perder el amor por él. Ello, en casos extremos puede explicar diversas conductas de maltrato hacia su hijo, transformando a su pareja en cómplice.

El recién nacido o lactante menor con disfunción en apego, también está muy tenso. Comprende a su manera, que algo no funciona bien, que no es entendido en sus demandas y que es, de cierto modo, agredido con la alimentación y demás procedimientos. Altera su ritmo de sueño y alimentación, padece de aerofagia y cólicos consecuentes, y desarrolla conductas reactivas a dicha agresión, con rechazo al exceso de alimentación y llantos excesivos e incontrolables. Ello, confunde más a su madre y se crea un círculo vicioso en el cual cada uno agrede y enferma al otro.

Una detección precoz de esta disfunción en el apego por un profesional de la salud con 
experiencia, puede revertir el problema y reencauzar el apego hacia una evolución normal. A veces sólo basta con explicar a los padres la naturaleza del problema y convencer a la madre de su real competencia en la crianza de su hijo para que el problema se solucione, y verificar en controles posteriores los resultados de la intervención. Otras veces, el problema es más complejo y requiere del apoyo del psiquiatra y/o psicologa.

\section{Recién nacido sano con apego normal}

- Está siempre contento.

- Mirada atenta, especialmente con su madre.

- Se calma en brazos de su madre.

- Buena succión y deglución.

- Manifiesta su hambre y plenitud.

- Adquiere un patrón de alimentación regular, sin cólicos.

\section{Recién nacido sano con apego patológico}

- Está irritable y/o dormilón.

- Mirada esquiva.

- No se calma en brazos de su madre (esta, lo mece constantemente).

- Succión pobre o descoordinado.

- Aerofagia y vómitos frecuentes.

- Llanto muy frecuente.

- Adquiere un patrón irregular de alimentación.

\section{Madre sana con apego normal}

- Contenta con su recién nacido.

- Tranquila frente al disconfort de su hijo.

- Alerta con sus demandas, que reconoce claramente.

- Muy positiva con su hijo.

- Reconoce y respeta su temperamento.

- Le ayuda a organizarse.

- Se adapta a su patrón y ritmo de alimentación.

\section{Madre sana con apego patológico}

- Ansiosa y deprimida frente al disconfort de su hijo.

- No entiende ni atiende bien demandas de su hijo.

- Muy estresada y sobreprotectora con su hijo.
- Desconoce su temperamento y ve atributos negativos en él.

- No detecta las claves de hambre o plenitud y tiende a sobrealimentarlo.

- Hipoestimula o sobreestimula.

- No logra un ritmo y patrón alimentario normal.

\section{Lactante de 6 a 12 meses sano con apego} normal

- Alerta, sonriente, feliz, reactivo.

- Mirada y actitudes proclives a la comunicación.

- Comunicación vocal, táctil y mimicogestual.

- Prefiere a sus padres, en vez de otros adultos.

- Disfruta la alimentación (¡Es un gourmeti).

- Comunica claramente hambre y saciedad.

- Patrón alimentario y de sueño bien regulados.

\section{Madre de hijo de 6 a 12 meses con apego normal}

- Placer consigo misma y su hijo.

- Comprometida y estimuladora.

- Ve atributos positivos en la conducta de su hijo.

- Alimentación placentera para ambos.

- Optima calidad y cantidad de lactancia y otros alimentos.

- Toma y acuna bien, en sus brazos a su hijo.

\section{Lactante de 6 a 12 meses con apego patológico}

- Triste, retraído e hipervigilante.

- Evita contacto visual.

- Vocaliza poco o no lo hace.

- Ausencia de conductas anticipatorios.

- Esquivo, al tomarle en brazos.

- Indiferente con los adultos.

- Vómitos frecuentes o rumiación.

- Indiferencia con su madre y la alimentación, pero no con la cuidadora.

Madre de lactante de 6 a 12 meses, con apego patológico

- Desapegada y deprimida.

- Ansiosa y agitada.

- Comparte poco tiempo con su hijo.

- Fallas en la interacción. 
- No responde ni entiende claves.

- El acto de alimentación es mecánico, sin afecto.

- Toma mal a su hijo, en sus brazos.

- Escaso contacto visual entre ambos.

- Indiferente con la nutrición de su hijo.

Con estos elementos de observación es posible detectar precozmente una disfunción en el apego, que habitualmente se asocia a problemas en la lactancia natural. Es de la más alta importancia que los profesionales de la salud sepan y puedan enfrentar esta situación. Un buen apego junto a una lactancia materna eficiente son determinantes para una excelente salud física y emocional del niño en el futuro, incluyendo un mejor coeficiente intelectual.

El gran desafío para los pediatras este siglo XXI, es lograr institucionalizar y transformarse en los paladines del apego y lactancia natural exclusiva durante los primeros seis meses de vida.

Para ello será preciso una mayor presencia en la comunidad a través de los medios informativos, continuar educando e investigando. Incorporar esta temática en el currículo de enseñanza básica y media, previo adiestramiento del magisterio. Incorporarla además, al currículo de todas las carreras relativas al área de la salud, comenzando por medicina, obstetricia y enfermería. Luchar por prolongar la Licencia Postnatal a seis meses y finalmente, predicando con el ejemplo.

El futuro de la humanidad está en el cerebro de los niños. Si cuidamos el cerebro, tanto físicamente como emocionalmente, desde la gestación hasta el término del desarrollo (edad pediátrica), con especial énfasis en el Apego y la Lactancia Natural Exclusiva, nuestros nietos vivirán en un mundo mejor.

\section{Referencias}

1.- Brazelton TB: Psycophysiologic reaction in the neonate and his behavior. J Pediatr 1961; 58: 513-8.

2.- Burnett CR, Leiderman PH: Neonatal separation: the maternal side of interaccional deprivation. Pediatrics 1970; 45: 197-205.
3.- Delgado A: Vida Clandestina. Edit. Imprenta Boan, Bilbao, España 1996.

4.- Díaz JL: La madre y su bebé: Primeras interacciones. Edit. RocaViva, Gnosos Ltda. Montevideo 1991.

5.- Dick-Read J: Childbirth without fear. Edit. Cox \& Wyneman, London 1979.

6.- Klaus M, Kennell J: Maternal - infant bonding. Edit CV Mosby Co, Saint Louis 1976.

7.- Harlow HF: Maternal behavior in mammals. Edit. John Wiley \& Sons Inc, New York 1963.

8.- Savage $K F$ : Helping mothers to breastfeed. African Medical and Research Foundation, Wilson Airport, Nairobi Kenya 1995.

9.- Klaus MH, Kennell JH, Plumb N, et al: Human maternal behavior at first contact with her young. Pediatrics 1970; 46: 187-92.

10.- Klaus M, Kennell J: Bonding. Edit Addison-Wesley Publishing Company Inc 1996.

11.- Klaus MH, Kennel JH: Mothering the Mother. Edit Addison-Wesley/Lawrence 1993.

12.- Klewsard L, Klaus M: The amazing Newborn. Edit Addison-Wesley/Lawrence 1985.

13.- Koning F: Tendremos un Hijo. Editorial Brugera, Barcelona 1979.

14.- Levin A: Human Perinatal Care. TEA Publishers, Tallin Estonia

15.- Martínez JC: El increíble universo del Recién Nacido. Editorial El Ateneo, Buenos Aires 2001.

16.- Michels HR: Breast Feeding. American Academy of Pediatrics 1981.

17.- Moneta ME: El Apego. Edit. Cuatro Vientos, Santiago Chile 2003.

18.- Muñoz C, Kaempfer AM, Castro R, Valenzuela S: Nacer en el siglo XXI: De vuelta a lo Humano. Universidad de Chile, Ministerio de Salud, Gobierno de Chile 2001.

19.- Odent M: La cientificación del amor: el amor en la ciencia. Editorial Creavida, Argentina 2001.

20.- Pinto F: Neurología Perinatal. RIL Editores, Medi Graphía 2002.

21.- Sociedad Chilena de Pediatría. Declaración de Pucón. XLI Congreso Chileno de Pediatría. 2001. Rev Chil Pediatr 2002; 73: 197.

22.- Royhard L, Blade MO: Effect of Delivery Routines on Success of First Breast feed. Lancet 1990; 336: 1105-7.

23.- Schanler RJ: The evidence for Breastfeeding. Pediatr Clin North Am 2001; 48: 201-6.

24.- Schanler RJ: The management of Breastfeeding. Pediatr Clin North Am 2001; 48: 316-25.

25.- Vargas $N$ : Puericultura: El cuidado de niños y jóvenes en el siglo XXI. Editorial Universitaria, Santiago Chile 2004.

26.- Villalón H, Lucero C, Álvarez P: Contacto precoz piel a piel: efecto sobre los parámetros fisiológicos en las cuatro horas posteriores al parto en recién nacidos de término sanos. Rev Chil Pediatr 1992; 63: 140-4. 